\title{
Self-Healing Thermal Annealing: Surface Morphological Restructuring Control of Nanorods
}

Michele Conroy, ${ }^{\dagger+s} \|^{*}$ Haoning Li, ${ }^{\dagger+}$ Vitaly Z. Zubialevich, ${ }^{\dagger}$ Michael Schmidt ${ }^{\dagger}$ Timothy Collins,

广\$" Michael Morris, ${ }^{\dagger} \|$ Colm Glynn, ${ }^{\S}$ Colm O'Dwyer, ${ }^{\S}$ Gunnar Kusch, ${ }^{\natural}$ Robert W. Martin, ${ }^{\natural}$

Justin D. Holmes, "广/ Peter J. Parbrook ${ }^{\dagger *}$

† Tyndall National Institute, Dyke Parade, Cork City, Ireland

\$School of Engineering, University College Cork, Cork City, Ireland

${ }^{\S}$ Department of Chemistry, University College Cork, Cork City, Ireland

॥AMBER@CRANN, Trinity College Dublin, Dublin City, Ireland

" Department of Physics, SUPA, University of Strathclyde, 107 Rottenrow, Glasgow G4 0NG, U.K.

ABSTRACT With advances in nanolithography and dry etching, top-down methods of nanostructuring have become a widely used tool for improving the efficiency of optoelectronics. These nano dimensions can offer various benefits to the device performance in terms of light extraction and efficiency, but often at the expense of emission colour quality. Broadening of the target emission peak and unwanted yellow luminescence are characteristic defect related 
effects due to the ion beam etching damage, particularly for III-N based materials. In this letter we focus on GaN based nanorods, showing that through thermal annealing the surface roughness and deformities of the crystal structure can be "self-healed". Correlative electron and atomic force microscopy (EM and AFM) shows the change from spherical nanorods to faceted hexagonal structures, revealing the temperature dependent surface morphology faceting evolution. The faceted nanorods were shown to be strain- and defect-free by cathodoluminescence (CL) hyperspectral imaging, micro-raman, and transmission electron microscopy (TEM). In-situ TEM thermal annealing experiments allowed for real time observation of dislocation movements and surface restructuring observed in ex-situ annealing TEM sampling. This thermal annealing investigation gives new in-sight to the redistribution path of GaN material and dislocation movement post growth, allowing for improved understanding and in turn advances in optoelectronic device processing of compound semiconductors.

In the past few years III-Ns have become the semiconductor material of choice for solid state lighting (SSL) at a global level. ${ }^{1-2}$ However III-N materials have two major drawbacks; firstly the high dislocation defect density due to the large lattice-mismatch at the heteroepitaxial interface of the non-native substrates. ${ }^{3-4}$ Secondly the polarization discontinuities in nitride-based heterostructures along the polar c-axis, inducing huge electric fields and in turn increasing the nonradiative recombination through the quantum confined Stark effect (QCSE). ${ }^{5-6}$ Overcoming the issue of device performance in III-Ns has been the intense focus of research worldwide. Some approaches include strain relief methods such as epitaxial lateral overgrowth, ${ }^{7-10}$ and suppressing the polarization field by growth on semi- and non-polar planes. ${ }^{11-13}$ Although these routes can reduce either the number of dislocations, or QCSE, the combined reduction of these issues has not 
been achieved. Moving from the classical bulk to nanostructured LEDs has shown to answer these problems collectively, ${ }^{14-17}$ while also providing many new optical properties associated with the nanoscale. ${ }^{18-19}$

To date the most common form of GaN nanorod growth is through molecular beam epitaxy where the nanorods are formed spontaneously in dense arrays. ${ }^{20-21}$ These densely packed arrays or nanorods have random orientations due to their spontaneously formed origins, leading to high levels of coalescence. At the point of coalescence inhomogeneous strain ${ }^{22-23}$ and nonradiative recombination centers ${ }^{21,24}$ are formed. Hence the theoretical benefits of growing GaN nanorods over bulk thin films for the platform of optoelectronic devices are not achieved in practice. A new two-step top-down/bottom-up approach to $\mathrm{GaN}$ nanorod formation has started to be utilized in the past few years ${ }^{25-27}$ to overcome these issues. This is where the benefits of bulk $\mathrm{GaN}$ thin films such as negligible point defect (carbon or oxygen) incorporation ${ }^{25}$ and bottom up grown nanorods' low strain and hence negligible dislocation density. ${ }^{28-29}$

The benefits of using these top-down formed $\mathrm{GaN}$ nanorods for strain reduction has been a wellestablished approach. ${ }^{30-31}$ However there has been no in-depth analysis on the effect of dislocation density. In our previous report for top-down formed AlN nanorods the TEM study suggest the annealing of the rods pre-growth reduces the dislocation density, ${ }^{32}$ but this dislocation movement/reduction has not been reported in GaN. In this article we report the first experimental in "real-time" proof of dislocation annihilation/movement post growth through simple annealing. The in-situ TEM investigation shows the movement of the dislocation with increasing thermal anneal temperature. We also demonstrate that the etch damage causing non-uniformity in near band emission (NBE) intensity distribution along the nanorod sidewall seen in hyperspectral CL mapping is suppressed after annealing. Surface roughening caused by the randomness of the 
impinging etch ions and resulting incorporation of defects/vacancies, is known to generate reduction in emission at the target wavelength and/or yellow emission, ${ }^{33-34}$ thus causing the variation in NBE. This processing step issue can now be overcome for nanorods through a simple annealing step.

(a)

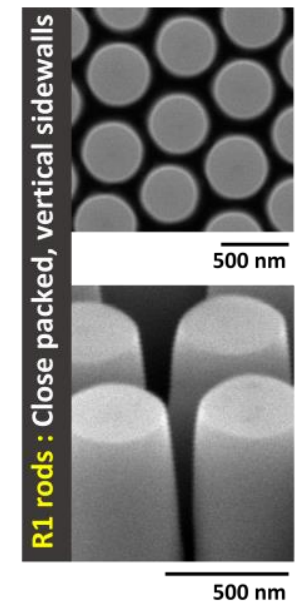

(b)

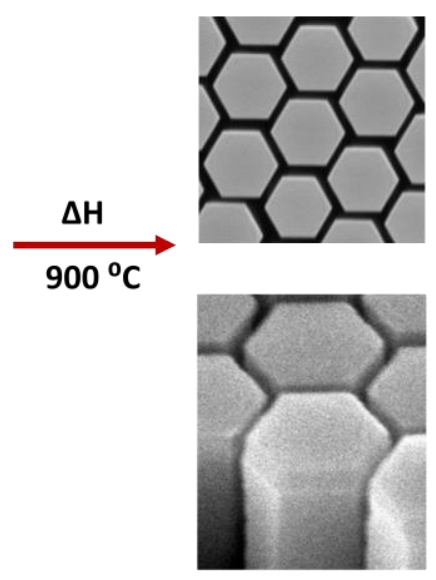

(c)

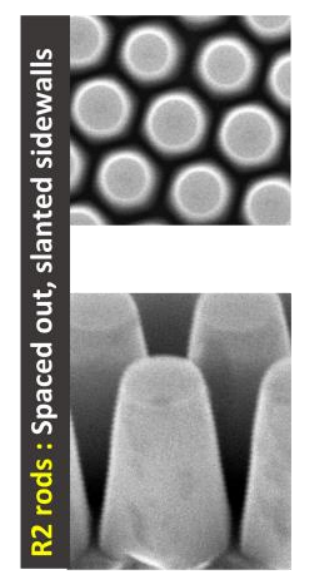

(d)

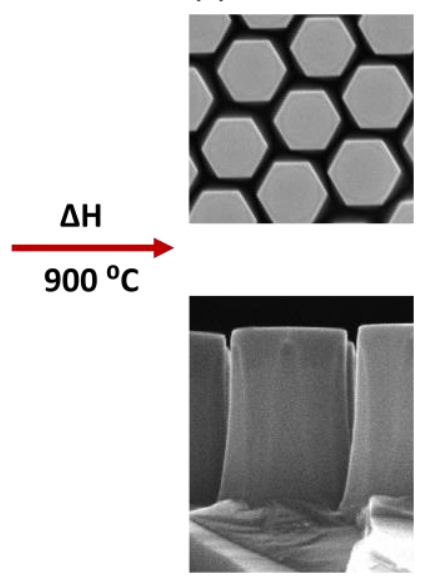

Figure 1. SEM surface analysis of R1 type nanorods (a) pre-anneal and (b) post $900{ }^{\circ} \mathrm{C}$ anneal, and R2 type nanorods (c) pre-anneal and (d) post $900{ }^{\circ} \mathrm{C}$ anneal.

The re-structuring effect on the circular nanorods due to the $900{ }^{\circ} \mathrm{C} 30 \mathrm{~min}$ thermal anneal is investigated by SEM, revealing the first report of self-facet recovery without growth as seen in Figure 1. As top-down formed III-N nanorods are often used as the "scaffold" for subsequent overgrowth, ${ }^{35-36}$ an initial thin growth layer is often used to recover the hexagonal shape for the active region growth. ${ }^{27}$ Through this simple annealing method the naturally occurring hexagonal non-polar facets can be recovered in a singular step without the need for $\mathrm{GaN}$ regrowth or passivation layers. The bulk GaN epi-layer grown by metal organic vapour phase epitaxy $\mathrm{MOCVD}^{37}$ on a sapphire 2" wafer was halved to produce two types of nanorod geometries on the same wafer for a fair materials characterization comparison of the nanorods later on; Figure 1a close packed nanorod pattern (R1) and Figure 1c spaced out nanorod pattern (R2). As described 
in our previous report, ${ }^{38}$ the initial etched nanorod geometry can determine the subsequent overgrowth and possible dislocation movement, hence it was important to analyse both types of patterns. The silica sphere mask was self-assembled by a scooping method and pattern transferred into the GaN MOCVD grown bulk layer as detailed in ref 32 and in supporting information.
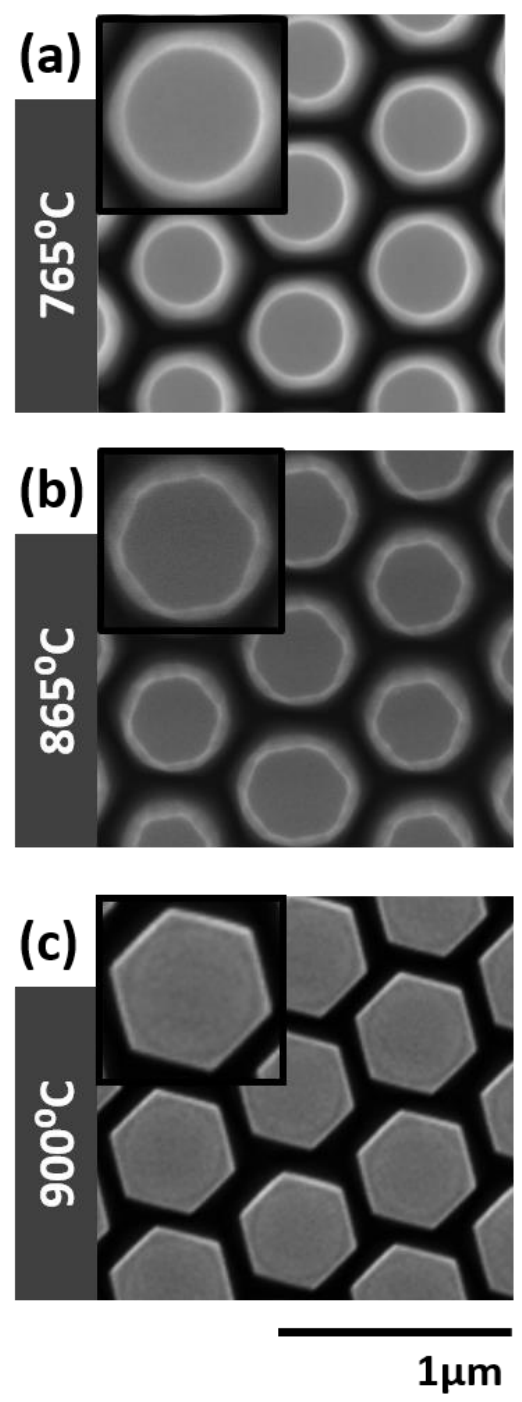
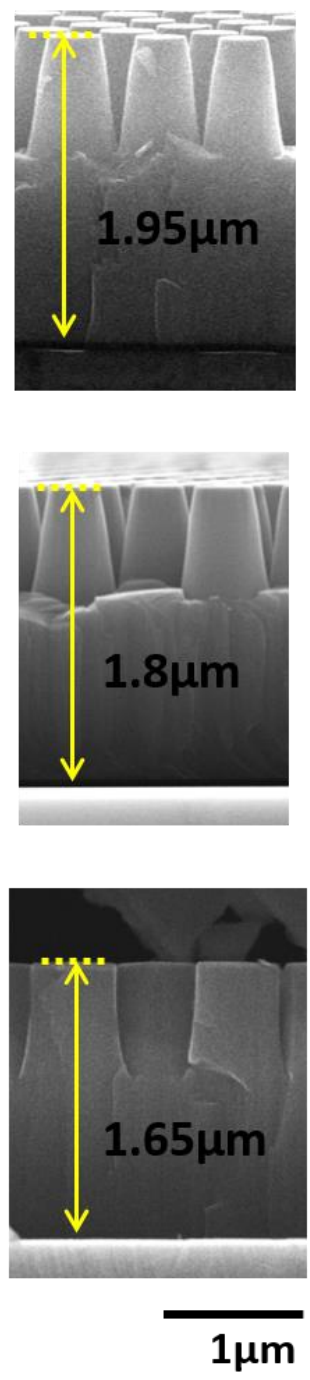

(d)

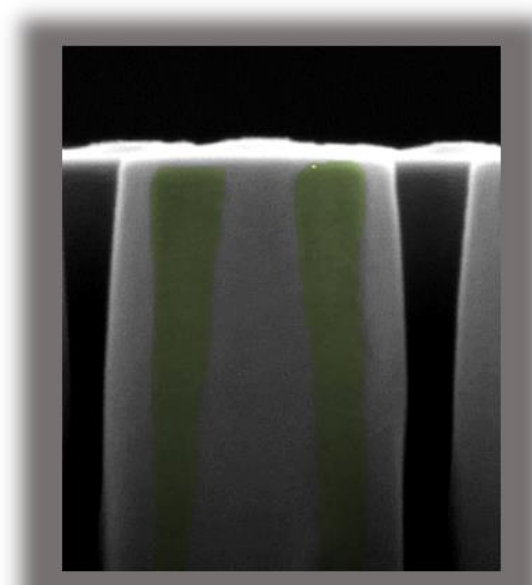

(e)

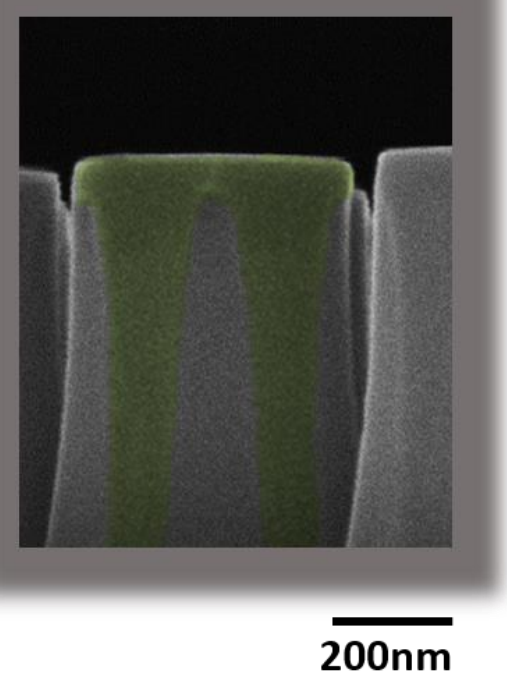

Figure 2. SEM scans of nanorod top surface and cross-section after anneals at (a) $765{ }^{\circ} \mathrm{C}$, (b) 865 ${ }^{0} \mathrm{C}$, (c) $900{ }^{\circ} \mathrm{C}$, (d) and (e) higher magnification cross sectional SEM scans of (b) and (c) samples respectively, with new non-polar facets highlighted yellow. 
Figure $1 \mathrm{~b}$ and $\mathrm{d}$ show the once circular etched nanorods have become hexagonal in shape, starting to fill out any free space between the nanorods. While the initial etched nanorod pattern (i.e. R1 or R2) does not appear to have any effect on the geometry of the hexagonal top surface as seen in top surface SEM images of Figure $1 \mathrm{~b}$ and $\mathrm{d}$. However the cross sectional SEM reveals a very different morphology. Interestingly the six non-polar sidewall facets for the spaced out pattern of R2, are only fully formed at the top of the nanorod with the facet width decreasing linearly downwards along the sidewall (seen Figure 1d and highlighted yellow in Figure 2e). There is a very clear indication from this non-polar pattern and the decreasing nanrods height $(1.95 \mu \mathrm{m} \rightarrow$ $1.65 \mu \mathrm{m}$ as seen in Figure 2c), that there is downwards movement of the material to form the faceted sidewalls. Due to the near perfectly vertical walls of R1 the formation of the non-polar facets appears to be a simple step resulting in evenly flat 1-100 hexagonal facets along the entire rod length, as in Figure 1c. However for R2 the slanted walls produce a barrier in achieving the correct angle (i.e. $90^{\circ}$ to the top surface) to form the non-polar 1-100 sidewalls. Even with this geometric barrier it is preferential for the non-polar sidewalls to form as seen in Figure 1d at the top of the nanorod.

In this letter we use the principle of Ga species desorption reported for high temperature anneal steps in fluxed growth methods ${ }^{39-40}$ to engineer the movement of $\mathrm{Ga}$ species, forming thermodynamically favorable smooth non-polar sidewalls. Initially the anneal temperature used was $900{ }^{\circ} \mathrm{C}$ as this was the temperature we use for growth of $\mathrm{GaN}$ bulk layers and nanorods. ${ }^{37}$ To study the effect of temperature on Ga species restructuring a range of growth temperatures was tried for R2 type GaN nanorods as seen in the SEM images of Figure 2. The lowest temperature of $765{ }^{\circ} \mathrm{C}$ had no effect on the overall height or top surface shape, Figure 2a. The higher temperature of $865^{\circ} \mathrm{C}$ showed a decrease in height and what appeared as a 12 sided top surface 
faceting from initial plan-view SEM, Figure 2b. As seen by cross sectional SEM in Figure 2d, these observed 12 facets in top down SEM imaging in Figure 2b, were in fact 6 non-polar sidewall facets beginning to form from the top and down the rod length. They had not however fully expanded out to encompass the entire rod perimeter, as highlighted in yellow at a higher magnification SEM scan (Figure 2d) of the non-polar sidewalls in Figure 2b. Anneal temperatures $>900{ }^{\circ} \mathrm{C}$ was tried as shown in supporting information showing the non-polar sidewalls stability increasing with increasing temperature ${ }^{41}$ however due to the roughening of the top surface the 900 ${ }^{\circ} \mathrm{C}$ was determined to be the ideal anneal temperature. As discussed above at $900{ }^{\circ} \mathrm{C}$ the 6 non polar sidewalls have fully formed along the entire rod length for R1 and at the top of the R2 nanorods, along with leaving an atomically flat top surface as seen in AFM scans in Figure 3.

High resolution plan-view SEM scans of the top surface of the nanorods a dark ring in the center of each nanorod was observed, as seen in Figure 2c. The diameter of these rings were found to be the same average diameter of the original circular nanorod before anneal. AFM topography scans of the top surface reveal a $\sim 2.3 \mathrm{~nm}$ downwards step across this dark line from the center of the rod to the outside, Figure $3 \mathrm{~b}$. This dark line is most likely due to the surface etch damage induced by the ion beam, ${ }^{26}$ which would cause a change in the chemical structure and hence the conductivity of the material. ${ }^{42}$ This leads one to believe the Ga species is re-distributing from the top surface to the form non-polar side walls on the etch-damaged original circular walls, as schematically illustrated in Figure 3a. The increasing c-plane nanorod top diameter with nanorod base diameter remaining the same width, and finally the rod length shrinking with increasing anneal temperature reveals a very clear trend in redistribution of $\mathrm{GaN}$ species downwards to form the non-polar sidewalls supporting the AFM data of Figure 3. 
To confirm the theory of downward distribution of Ga species to form the thermodynamically favourable non-polar side facets, the nanorod sidewalls were coated with $\mathrm{SiO}_{2}$ around the circular sidewalls as described by Le Boulbar et $\mathrm{al}^{27}$ and in the supporting information, pre-anneal. Only the top surface of the $\mathrm{GaN}$ nanorod was freed of $\mathrm{SiO}_{2}$ coating, to eliminate the possibility of contribution from the base of the nanorods upwards to the sidewalls. The SEM surface morphology investigation of these annealed $\mathrm{SiO}_{2}$ coated nanorods reveals the change to the six sided hexagonal shape at the top of the nanorod as seen in Figure $3 \mathrm{c}$ and $\mathrm{d}$. However it is also easy to see from these SEM scans this hexagonal geometry is only at the top of the nanorod where the GaN was exposed. There is also clear indication of downwards movement of Ga species on the $\mathrm{SiO}_{2}$ walls of the rods, however as the species cannot grow epitaxially on this amorphous surface the layer is rough indicating possibly a polycrystalline layer.

(a)

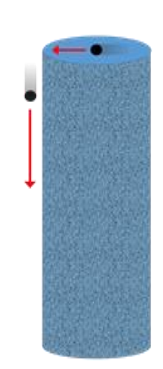

(b)

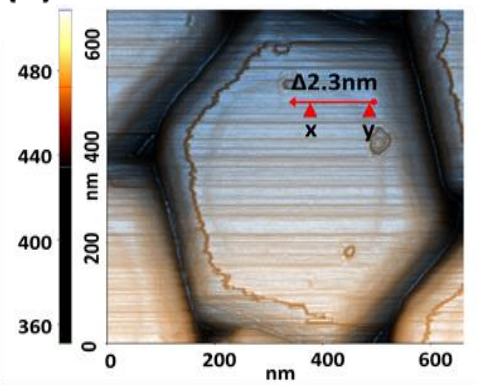

(c)

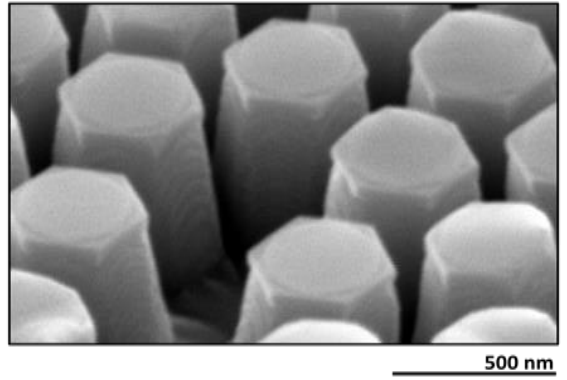

(d)

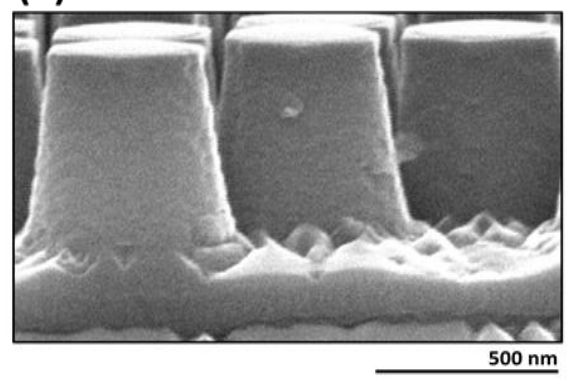

Figure 3. (a) schematic illustration of the change in morphology and decreasing height after annealing, (b) AFM scan revealing the downwards step at this boundary, (c) and (d) SEM scans of the $\mathrm{GaN}$ nanorods with a $\mathrm{SiO}_{2}$ sidewall coating after annealing at $900{ }^{\circ} \mathrm{C}$. 
The TEM investigation of the ex-situ annealed silica coated $\mathrm{R} 2$ nanorod pattern in a cross section focused ion beam (FIB) lamella show that no dislocations reach the top surface but instead appear to bend out at the non-polar walls (Figure 4a and supporting information), as we reported for AlN nanorods. ${ }^{32}$ In-situ TEM thermal annealing investigation was conducted on a FIB cross-section of the pre-anneal R2 rods along the 11-20 zone axis for real time observation of dislocation movement (Figure 4b). During the temperature ramp to $900{ }^{\circ} \mathrm{C}$ the nanorod height was decreased with increasing surface roughening (Figure $4 b$ ), as seen for some ex-situ annealed nanorods with $\mathrm{SiO}_{2}$ coating under SEM (supporting information) and TEM (Figure 4a). After $\sim 5$ mins of annealing time with the temperature held at $900{ }^{0} \mathrm{C}$ the dislocation bent out of the film in the 10-10 plane, Figure $4 b$, leaving a dislocation core appearing brighter in the TEM micrograph (marked with *). The in-situ TEM investigation enables the study of dislocation movement in real time in III-N thin films post growth that has not be reported until now. After a suitable temperature and anneal time is reached the end point of the dislocation is more kinetically favorable at the non-polar facted sidewall of the nanorods than to terminate at the top surface of the nanorod, resulting in a dislocation free top surface. These GaN nanorods can be used as high crystal quality templates for overgrowth.

(a)

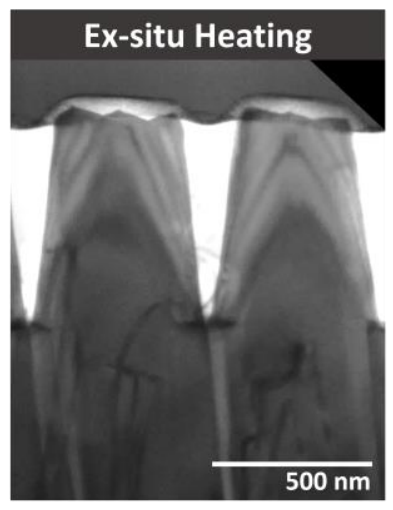

(b)

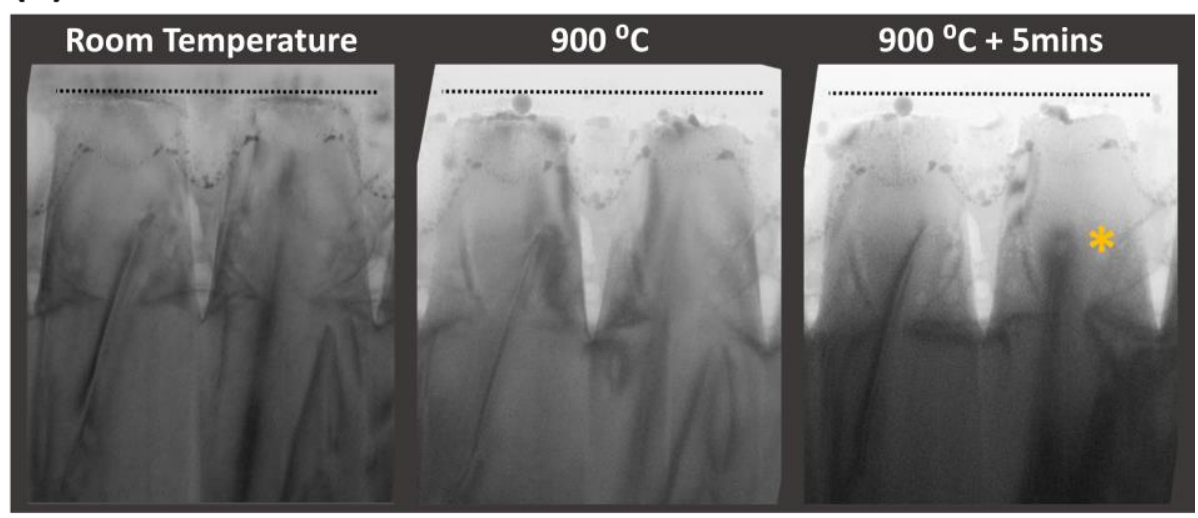

Figure 4. TEM image of $\mathrm{R} 2 \mathrm{GaN}$ nanorods after (a) ex-situ $900{ }^{\circ} \mathrm{C}$ and (b) in-situ $900^{\circ} \mathrm{C}$ anneal. 
It is well accepted that the reduction in dimensions from bulk the GaN layer to the nanorods after etching results in a lowering of the strain within the nanostructured material. ${ }^{30-31}$ Hyperspectral CL mapping and micro Raman was used to investigate the change in strain within the GaN nanorods after annealing. The $\mathrm{CL}$ intensity maps of the $\mathrm{GaN}$ nanorods reveal the striking change in variable intensity along the length of these rods before and after annealing. The CL intensity maps of the GaN nanorods before and after the annealing process (Figure $5 \mathrm{a}$ and $\mathrm{b}$ respectively) exhibit a strong change in the GaN NBE intensity distribution along the nanorods. The CL map of the non-annealed nanorods in Figure 5a show a non-uniform intensity distribution along the nanorod sidewalls with a clear intensity maximum on the c-plane facet on top of the nanorod. The annealed nanorods (Figure $5 \mathrm{~b}$ ) on the other hand show a much more homogenous intensity distribution along the nanorod sidewalls. The degradation of the NBE emission intensity along the non-annealed nanorod is most likely caused by effects of the etching process. One effect is that due to the randomness of impinging etch ions the nanorod sidewalls will be left with an increased surface roughness compared to the c-plane facet ${ }^{33}$ reducing the emission intensity. The second effect is that during the etching process the removal of $\mathrm{N}$ atoms is enhanced compared to Ga atoms. ${ }^{43}$ This leaves Ga-rich nanorod sidewalls to which either impurities can bound ${ }^{34,44}$ or on which vacancies be incorporated. Incorporated defects and vacancies can either act as nonradiative recombination centers or emit yellow luminescence. Especially $\mathrm{O}$ bound to $\mathrm{Ga}$ atoms have been reported to degrade the luminescence intensity. ${ }^{43}$ The high temperature annealing appears to heal the etch damage and in turn approving the luminescent properties of the GaN.

Micro Raman scattering spectroscopy analysis of the bulk GaN before(black line) and after the R2 type etch(red line) seen in Figure 5c clearly shows the blue shift of the $\mathrm{E}_{1}(\mathrm{TO}) / \mathrm{E}_{2}^{\text {high }}$ mode peak and separation of peaks from $571.56 \mathrm{~cm}^{-1}$ to $567.48 \mathrm{~cm}^{-1}$. It should be noted that polar thin 
films of wurzite bulk GaN layers grown in the 0001 direction on AlN of the same crystallographic orientation will result in a compressively strained GaN layer. ${ }^{45}$ Hence the blue shift in the tensile strain direction seen in Figure $5 \mathrm{c}$ of the red peak, is in fact an indication of the decreased strain. The separation of the $E_{1}(\mathrm{TO})$ and $\mathrm{E}_{2}^{\text {high }}$ mode peaks for the $\mathrm{R} 2$ type etched nanorods can be explained by the significant variation of strain from the top of the nanrod to the base and the change in surface morphology unlike the more uniformly strained bulk GaN with a smooth surface (black line Figure 5c). ${ }^{46}$ This strong correlation between the surface morphology (and their crystal orientations) and the phonon spectra of III-Ns is well known feature used in Raman spectroscopy analysis of III-N nanostructures..$^{47-49}$ The same $\mathrm{R} 2$ nanorods after anneal at $900{ }^{\circ} \mathrm{C}$ reunifies $\mathrm{E}_{1}(\mathrm{TO})$ and $\mathrm{E}_{2}^{\text {high }}$ mode peaks with the peak location blue shifted from the bulk to $569.11 \mathrm{~cm}^{-1}$, blue line in Figure 5c indicating a decrease strain with a more homogenous surface morphology (i.e. nonpolar smooth facets formed covering the rough circular etch sidewall as seen in Figure 1 and 2).

(a)
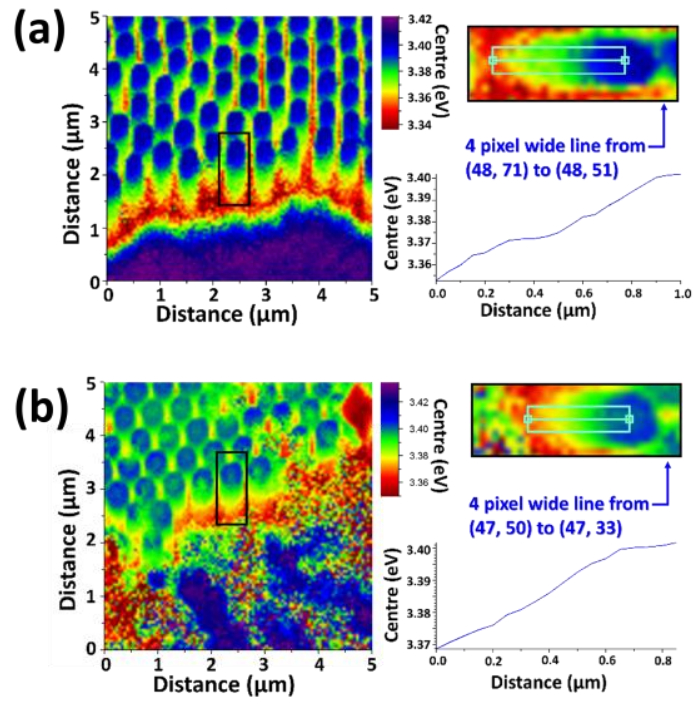

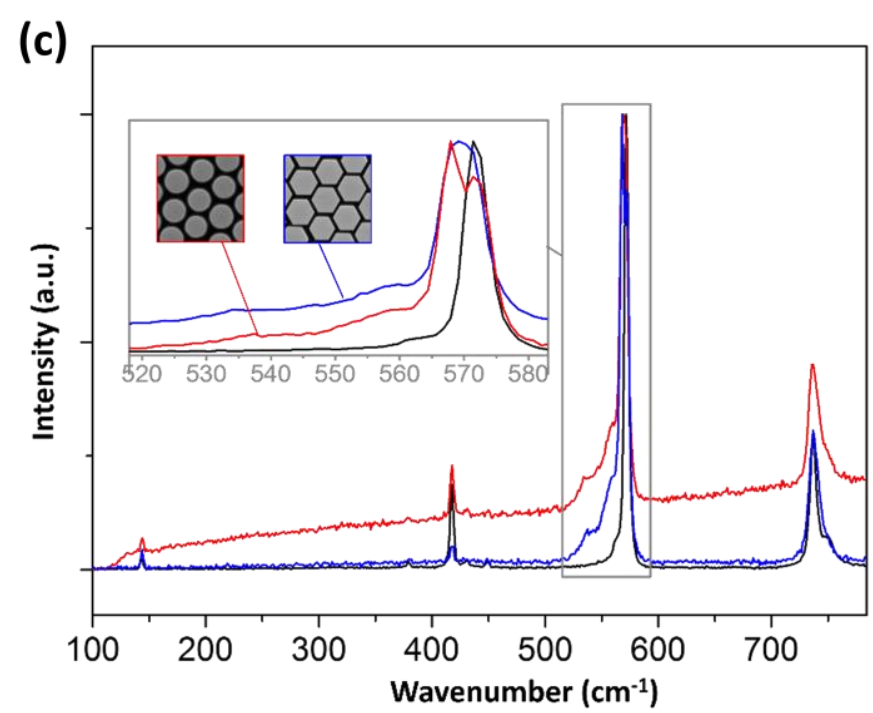

Picture 5. Hyperspectral CL of (a) GaN nanorods after etching, (b) GaN nanorods in (a) after annealing at $900{ }^{\circ} \mathrm{C}$, with insets of intensity line spectra, (c) micro Raman spectra of (a) and (b). 
In conclusion this article reports for the first time dislocation annihilation in GaN post-growth by a simply annealing the nanostructured bulk layer, and in turn increasing the crystal quality of the thin film. The surface morphology faceting evolution during the annealing step that results in a decrease in rod length with increasing temperature is described by the downwards redistribution of Ga species to form the kinetically stable m-planes. This theory is supported by the downwards step seen by AFM from the center rod diameter to the newly formed non-polar sidewalls that is visualized as a dark circle in the SEM. Finally through correlative Raman and cathodoluminescence (CL) studies of the etched nanorods before and after annealing shows the reduction in strain and etching damage through the applied thermal energy. It is clear from the results that during annealing it is thermodynamically favorable for Ga species to redistribute to form the lowest energy geometry hence 6 sided non-polar faceted nanorods are observed instead of staying circular.

\section{AUTHOR INFORMATION}

\section{Corresponding Author}

*Address correspondence to: micheleannconroy@gmail.com and peter.parbrok@tyndall.ie

\section{Present Addresses}

$\dagger \& \|$ Michele Conroy: Pacific Northwest National Laboratory, 902 Battelle Blvd, Richland, WA 99354, United States.

\section{Author Contributions}

M.C and P.J.P conceived the idea. M.C., H.L., and V.Z.Z. performed the MOCVD growth and exsitu annealing. M. C. performed the SEM, FIB and TEM. M.C. and M.S. performed the in-situ 
TEM thermal annealing. T.C. performed the AFM under supervision of M.A.M.. CG performed the Raman characterization under the supervision of C.D.. G.K. performed the CL under the supervision of R.W.M.. M.C. wrote the manuscript. J.D.H. and P.J.P supervised the project.

The manuscript was written through contributions of all authors. All authors have given approval to the final version of the manuscript.

Conflict of Interest: The authors declare no competing financial interest.

Supporting Information Available:

This material is available free of charge via the Internet at http:// pubs.acs.org.

Details on the self-assembling patterning method, SEM scans of the $1000{ }^{\circ} \mathrm{C}$ and $1100{ }^{\circ} \mathrm{C}$ anneal results, schematic illustration of the $\mathrm{SiO}_{2}$ coating, TEM of the ex-situ annealed nanorods, SEM cross section of the $\mathrm{SiO}_{2}$ coated annealed nanorods.

Acknowledgment. This research was enabled by the Irish Higher Education Authority Programme for Research in Third Level Institutions Cycles 4 and 5 via the INSPIRE and TYFFANI projects, and by Science Foundation Ireland (SFI) under Grant no. SFI/10/IN.1/I2993. PJP acknowledges funding from SFI Engineering Professorship scheme (07/EN/E001A) and MC acknowledges PhD research scholarship from INSPIRE. This work was conducted under the framework of the Irish Government's Programme for Research in Third Level Institutions Cycle 5, National Development Plan 2007-2013 with the assistance of the European Regional Development Fund. 


\section{REFERENCES}

1. DenBaars, S. P.; Feezell, D.; Kelchner, K.; Pimputkar, S.; Pan, C.-C.; Yen, C.-C.; Tanaka, S.; Zhao, Y.; Pfaff, N.; Farrell, R.; Iza, M.; Keller, S.; Mishra, U.; Speck, J. S.; Nakamura, S., Development of gallium-nitride-based light-emitting diodes (LEDs) and laser diodes for energy-efficient lighting and displays. Acta Materialia 2013, 61 (3), 945-951.

2. $\quad$ Humphreys, C. J., Solid-State Lighting. MRS Bulletin 2008, 33 (04), 459-470.

3. Wu, X. H.; Fini, P.; Tarsa, E. J.; Heying, B.; Keller, S.; Mishra, U. K.; DenBaars, S. P.; Speck, J. S., Dislocation generation in GaN heteroepitaxy. Journal of Crystal Growth 1998, 189190, 231-243.

4. Tomoya, S.; Hisao, S.; Maosheng, H.; Yoshiki, N.; Satoshi, K.; Satoru, T.; Kenji, Y.; Katsushi, N.; Linda, T. R.; Shiro, S., Direct Evidence that Dislocations are Non-Radiative Recombination Centers in GaN. Japanese Journal of Applied Physics 1998, 37 (4A), L398. 5. Tetsuya, T.; Shigetoshi, S.; Maki, K.; Miho, K.; Hideo, T.; Hiroshi, A.; Isamu, A., Quantum-Confined Stark Effect due to Piezoelectric Fields in GaInN Strained Quantum Wells. Japanese Journal of Applied Physics 1997, 36 (4A), L382.

6. Jain, S. C.; Willander, M.; Narayan, J.; Overstraeten, R. V., III-nitrides: Growth, characterization, and properties. Journal of Applied Physics 2000, 87 (3), 965-1006.

7. Beaumont, B.; Gibart, P.; Vaille, M.; Haffouz, S.; Nataf, G.; Bouillé, A., Lateral overgrowth of $\mathrm{GaN}$ on patterned $\mathrm{GaN} /$ sapphire substrate via selective metal organic vapour phase epitaxy: a route to produce self supported GaN substrates. Journal of Crystal Growth 1998, 189-190 (0), 97-102.

8. Vennéguès, P.; Beaumont, B.; Bousquet, V.; Vaille, M.; Gibart, P., Reduction mechanisms for defect densities in GaN using one- or two-step epitaxial lateral overgrowth methods. Journal of Applied Physics 2000, 87 (9), 4175-4181.

9. $\quad$ Nakamura, S.; Senoh, M.; Nagahama, S.-i.; Iwasa, N.; Yamada, T.; Matsushita, T.; Kiyoku, H.; Sugimoto, Y.; Kozaki, T.; Umemoto, H., InGaN/GaN/AlGaN-based laser diodes with modulation-doped strained-layer superlattices grown on an epitaxially laterally overgrown GaN substrate. Applied Physics Letters 1998, 72, 211.

10. Zeimer, U.; Kueller, V.; Knauer, A.; Mogilatenko, A.; Weyers, M.; Kneissl, M., High quality AlGaN grown on ELO AlN/sapphire templates. Journal of Crystal Growth 2013, 377 (0), 32-36.

11. Sawaki, N.; Hikosaka, T.; Koide, N.; Tanaka, S.; Honda, Y.; Yamaguchi, M., Growth and properties of semi-polar GaN on a patterned silicon substrate. Journal of Crystal Growth 2009, 311 (10), 2867-2874.

12. Park, S.-H.; Ahn, D., Depolarization effects in $\left(112^{-} 2\right)$-oriented InGaNGaN quantum well structures. Applied Physics Letters 2007, 90 (1), 013505.

13. Masui, H.; Nakamura, S.; DenBaars, S. P.; Mishra, U. K., Nonpolar and Semipolar IIINitride Light-Emitting Diodes: Achievements and Challenges. Electron Devices, IEEE Transactions on 2010, 57 (1), 88-100.

14. Waag, A.; Wang, X.; Fündling, S.; Ledig, J.; Erenburg, M.; Neumann, R.; Al Suleiman, M.; Merzsch, S.; Wei, J.; Li, S.; Wehmann, H. H.; Bergbauer, W.; Straßburg, M.; Trampert, A.; Jahn, U.; Riechert, H., The nanorod approach: GaN NanoLEDs for solid state lighting. physica status solidi (c) 2011, 8 (7-8), 2296-2301.

15. Colby, R.; Liang, Z.; Wildeson, I. H.; Ewoldt, D. A.; Sands, T. D.; García, R. E.; Stach, E. A., Dislocation Filtering in GaN Nanostructures. Nano Letters 2010, 10 (5), 1568-1573. 
16. Yeh, T.-W.; Lin, Y.-T.; Stewart, L. S.; Dapkus, P. D.; Sarkissian, R.; O’Brien, J. D.; Ahn, B.; Nutt, S. R., InGaN/GaN multiple quantum wells grown on nonpolar facets of vertical $\mathrm{GaN}$ nanorod arrays. Nano letters 2012, 12 (6), 3257-3262.

17. Lin, H.-W.; Lu, Y.-J.; Chen, H.-Y.; Lee, H.-M.; Gwo, S., InGaN/GaN nanorod array white light-emitting diode. Applied Physics Letters 2010, 97 (7), 073101.

18. Ko, Y.-H.; Kim, J.-H.; Gong, S.-H.; Kim, J.; Kim, T.; Cho, Y.-H., Red Emission of InGaN/GaN Double Heterostructures on GaN Nanopyramid Structures. ACS Photonics 2015, 2 (4), 515-520.

19. Wright, J. B.; Liu, S.; Wang, G. T.; Li, Q.; Benz, A.; Koleske, D. D.; Lu, P.; Xu, H.; Lester, L.; Luk, T. S.; Brener, I.; Subramania, G., Multi-Colour Nanowire Photonic Crystal Laser Pixels. Sci. Rep. 2013, 3.

20. $\quad$ Geelhaar, L.; Che; x; ze, C.; Jenichen, B.; Brandt, O.; Pfu; x; ller, C.; Mu; x; nch, S.; Rothemund, R.; Reitzenstein, S.; Forchel, A.; Kehagias, T.; Komninou, P.; Dimitrakopulos, G. P.; Karakostas, T.; Lari, L.; Chalker, P. R.; Gass, M. H.; Riechert, H., Properties of GaN Nanowires Grown by Molecular Beam Epitaxy. Selected Topics in Quantum Electronics, IEEE Journal of 2011, 17 (4), 878-888.

21. Brandt, O.; Fernández-Garrido, S.; Zettler, J. K.; Luna, E.; Jahn, U.; Chèze, C.; Kaganer, V. M., Statistical Analysis of the Shape of One-Dimensional Nanostructures: Determining the Coalescence Degree of Spontaneously Formed GaN Nanowires. Crystal Growth \& Design 2014, 14 (5), 2246-2253.

22. Kaganer, V.; Jenichen, B.; Brandt, O.; Fernández-Garrido, S.; Dogan, P.; Geelhaar, L.; Riechert, H., Inhomogeneous strain in GaN nanowires determined from x-ray diffraction peak profiles. Physical Review B 2012, 86 (11), 115325.

23. Jenichen, B.; Brandt, O.; Pfueller, C.; Dogan, P.; Knelangen, M.; Trampert, A., Macroand micro-strain in GaN nanowires on Si (111). Nanotechnology 2011, 22 (29), 295714.

24. Consonni, V.; Knelangen, M.; Jahn, U.; Trampert, A.; Geelhaar, L.; Riechert, H., Effects of nanowire coalescence on their structural and optical properties on a local scale. Applied Physics Letters 2009, 95 (24), 241910.

25. Coltrin, M. E.; Armstrong, A. M.; Brener, I.; Chow, W. W.; Crawford, M. H.; Fischer, A. J.; Kelley, D. F.; Koleske, D. D.; Lauhon, L. J.; Martin, J. E.; Nyman, M.; Schubert, E. F.; SheaRohwer, L. E.; Subramania, G.; Tsao, J. Y.; Wang, G. T.; Wierer, J. J.; Wright, J. B., Energy Frontier Research Center for Solid-State Lighting Science: Exploring New Materials Architectures and Light Emission Phenomena. The Journal of Physical Chemistry C 2014, 118 (25), 13330-13345.

26. Li, Q.; Westlake, K. R.; Crawford, M. H.; Lee, S. R.; Koleske, D. D.; Figiel, J. J.; Cross, K. C.; Fathololoumi, S.; Mi, Z.; Wang, G. T., Optical performance of top-down fabricated InGaN/GaN nanorod light emitting diode arrays. Opt. Express 2011, 19 (25), 25528-25534.

27. Le Boulbar, E. D.; Gîrgel, I.; Lewins, C. J.; Edwards, P. R.; Martin, R. W.; Šatka, A.; Allsopp, D. W. E.; Shields, P. A., Facet recovery and light emission from GaN/InGaN/GaN coreshell structures grown by metal organic vapour phase epitaxy on etched GaN nanorod arrays.

Journal of Applied Physics 2013, 114 (9), 094302.

28. Li, S.; Waag, A., GaN based nanorods for solid state lighting. Journal of Applied Physics 2012, $111(7),-$.

29. Zubia, D.; Hersee, S. D., Nanoheteroepitaxy: The Application of nanostructuring and substrate compliance to the heteroepitaxy of mismatched semiconductor materials. Journal of Applied Physics 1999, 85 (9), 6492-6496. 
30. Keller, S.; Schaake, C.; Fichtenbaum, N. A.; Neufeld, C. J.; Wu, Y.; McGroddy, K.; David, A.; DenBaars, S. P.; Weisbuch, C.; Speck, J. S.; Mishra, U. K., Optical and structural properties of $\mathrm{GaN}$ nanopillar and nanostripe arrays with embedded InGaN/GaN multi-quantum wells. Journal of Applied Physics 2006, 100 (5), 054314.

31. Xie, E. Y.; Chen, Z. Z.; Edwards, P. R.; Gong, Z.; Liu, N. Y.; Tao, Y. B.; Zhang, Y. F.; Chen, Y. J.; Watson, I. M.; Gu, E.; Martin, R. W.; Zhang, G. Y.; Dawson, M. D., Strain relaxation in InGaN/GaN micro-pillars evidenced by high resolution cathodoluminescence hyperspectral imaging. Journal of Applied Physics 2012, 112 (1), 013107.

32. Conroy, M.; Zubialevich, V. Z.; Li, H.; Petkov, N.; Holmes, J. D.; Parbrook, P. J., Epitaxial lateral overgrowth of AlN on self-assembled patterned nanorods. Journal of Materials Chemistry C 2015, 3 (2), 431-437.

33. Choi, H. W.; Chua, S. J.; Tripathy, S., Morphological and structural analyses of plasmainduced damage to n-type GaN. Journal of Applied Physics 2002, 92 (8), 4381-4385.

34. Xu, S.; Hao, Y.; Zhang, J.; Jiang, T.; Yang, L.; Lu, X.; Lin, Z., Yellow Luminescence of Polar and Nonpolar GaN Nanowires on r-Plane Sapphire by Metal Organic Chemical Vapor Deposition. Nano Letters 2013, 13 (8), 3654-3657.

35. Chang, J.-R.; Chang, S.-P.; Li, Y.-J.; Cheng, Y.-J.; Sou, K.-P.; Huang, J.-K.; Kuo, H.-C.; Chang, C.-Y., Fabrication and luminescent properties of core-shell InGaN/GaN multiple quantum wells on GaN nanopillars. Applied Physics Letters 2012, 100 (26), 261103.

36. Krylyuk, S.; Paramanik, D.; King, M.; Motayed, A.; Ha, J.-Y.; Bonevich, J. E.; Talin, A.; Davydov, A. V., Large-area GaN n-core/p-shell arrays fabricated using top-down etching and selective epitaxial overgrowth. Applied Physics Letters 2012, 101 (24), 241119.

37. Conroy, M.; Li, H.; Kusch, G.; Zhao, C.-L.; Edwards, P. R.; Ooi, B. S.; Martin, R. W.; Holmes, J. D.; Parbrook, P. J., Site controlled Red-Yellow-Green light emitting InGaN Quantum Discs on nano-tipped GaN rods RSC Nanoscale. Nanoscale 2016, In-Press.

38. Conroy, M.; Zubialevich, V. Z.; Li, H.; Petkov, N.; O'Donoghue, S.; Holmes, J. D.; Parbrook, P. J., Ultra-High Density Arrays of Defect Free AlN Nanorods: A 'Space Filling' Approach. ACS Nano $\mathbf{2 0 1 5 .}$

39. Yen-Ting, L.; Ting-Wei, Y.; Dapkus, P. D., Mechanism of selective area growth of GaN nanorods by pulsed mode metalorganic chemical vapor deposition. Nanotechnology 2012, 23 (46), 465601.

40. Bae, S.-Y.; Jung, B. O.; Lekhal, K.; Kim, S. Y.; Lee, J. Y.; Lee, D.-S.; Deki, M.; Honda, Y.; Amano, H., Highly elongated vertical GaN nanorod arrays on Si substrates with an AlN seed layer by pulsed-mode metal-organic vapor deposition. CrystEngComm 2016.

41. Hiramatsu, K.; Nishiyama, K.; Motogaito, A.; Miyake, H.; Iyechika, Y.; Maeda, T., Recent Progress in Selective Area Growth and Epitaxial Lateral Overgrowth of III-Nitrides: Effects of Reactor Pressure in MOVPE Growth. physica status solidi (a) 1999, 176 (1), 535-543. 42. Kim, K. H.; Akase, Z.; Suzuki, T.; Shindo, D., Charging effects on SEM/SIM contrast of metal/insulator system in various metallic coating conditions. Materials transactions 2010, 51 (6), 1080-1083.

43. Choi, H. W.; Chua, S. J.; Raman, A.; Pan, J. S.; Wee, A. T. S., Plasma-induced damage to n-type GaN. Applied Physics Letters 2000, 77 (12), 1795-1797.

44. Wang, C.-Y.; Chen, L.-Y.; Chen, C.-P.; Cheng, Y.-W.; Ke, M.-Y.; Hsieh, M.-Y.; Wu, H.M.; Peng, L.-H.; Huang, J., GaN nanorod light emitting diode arrays with a nearly constant electroluminescent peak wavelength. Opt. Express 2008, 16 (14), 10549-10556. 
45. Hiroshi, A.; Motoaki, I.; Takayuki, K.; Maki, K.; Isamu, A.; Jung, H.; Sean, H.; Jerry, A. F.; Eric, C.; Jeffrey, F., Stress and Defect Control in GaN Using Low Temperature Interlayers. Japanese Journal of Applied Physics 1998, 37 (12B), L1540.

46. Hsiao, C.-L.; Tu, L.-W.; Chi, T.-W.; Chen, M.; Young, T.-F.; Chia, C.-T.; Chang, Y.-M., Micro-Raman spectroscopy of a single freestanding $\mathrm{GaN}$ nanorod grown by molecular beam epitaxy. Applied Physics Letters 2007, 90 (4), 043102.

47. Sahoo, P., S. Dhara, S. Dash, A. K. Tyagi, Baldev Raj, C. R. Das, P. Chandramohan, M. P. Srinivasan, Surface optical modes in GaN nanowires. International Journal of Nanotechnology 2010, 7 (9-12), 823-832.

48. Patsha, A.; Sahoo, P.; Dhara, S.; Amirthapandian, S.; Tyagi, A. K., Probing crystallographic orientation of a single GaN nanotube using polarized Raman imaging. Journal of Raman Spectroscopy 2013, 44 (5), 651-654.

49. Sahoo, P.; Dhara, S.; Amirthapandian, S.; Kamruddin, M.; Dash, S.; Panigrahi, B. K.; Tyagi, A. K., Role of Surface Polarity in Self-Catalyzed Nucleation and Evolution of GaN Nanostructures. Crystal Growth \& Design 2012, 12 (5), 2375-2381. 


\section{Supporting Information}

\section{Self-Healing Thermal Annealing: Surface Morphological Restructuring Control of Nanorods}

Michele Conroy, ${ }^{\dagger+\|^{*}}$ Haoning Li, ${ }^{\dagger+}$ Vitaly Z. Zubialevich, ${ }^{\dagger}$ Gunnar Kusch, ${ }^{\natural}$ Michael Schmidt, ${ }^{\dagger}$ Timothy Collins, ${ }^{\dagger}{ }^{\|}$Colm Glynn, ${ }^{\S}$ Robert W. Martin, ${ }^{\circledR}$ Colm O'Dwyer, ${ }^{\S}$ Michael D. Morris, ${ }^{\dagger \$} \|$ Justin D. Holmes, ${ }^{\dagger /}$ Peter J. Parbrook $k^{\dagger *}$

${ }^{\dagger}$ Tyndall National Institute, Dyke Parade, Cork City, Ireland

\$School of Engineering, University College Cork, Cork City, Ireland

${ }^{\S}$ Department of Chemistry, University College Cork, Cork City, Ireland

"AMBER@CRANN, Trinity College Dublin, Dublin City, Ireland

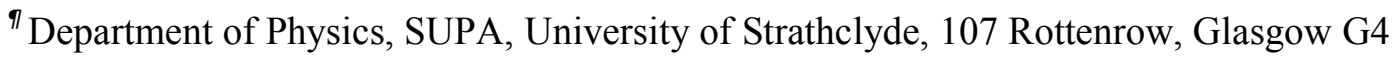
0NG, U.K. 
(a)

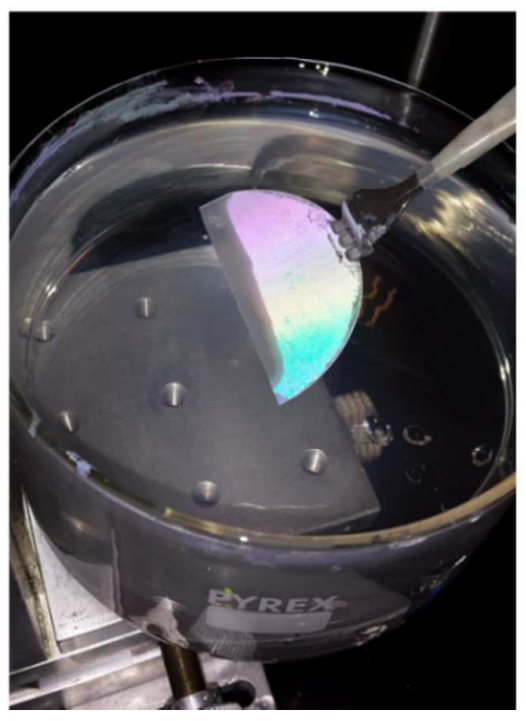

(b)

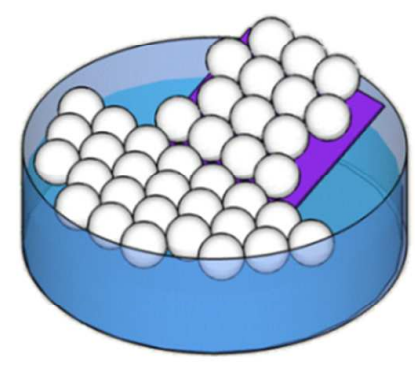

(c)

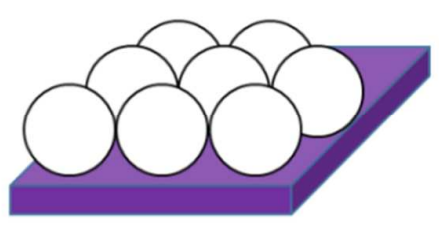

Figure S1. (a) Photograph of a half 2" GaN/AlN/Sapphire wafer above the scooping apparatus used to assemble of monolayer of silica spheres, the area of wafer air dried clearly shows the monolayer seen by the "rainbow" colouring, (b) Illustration of the water-air selfassembly process seen in photograph (a), (c) illustration of the hexagonally close packed spheres on substrate. 
High Temperature Anneal
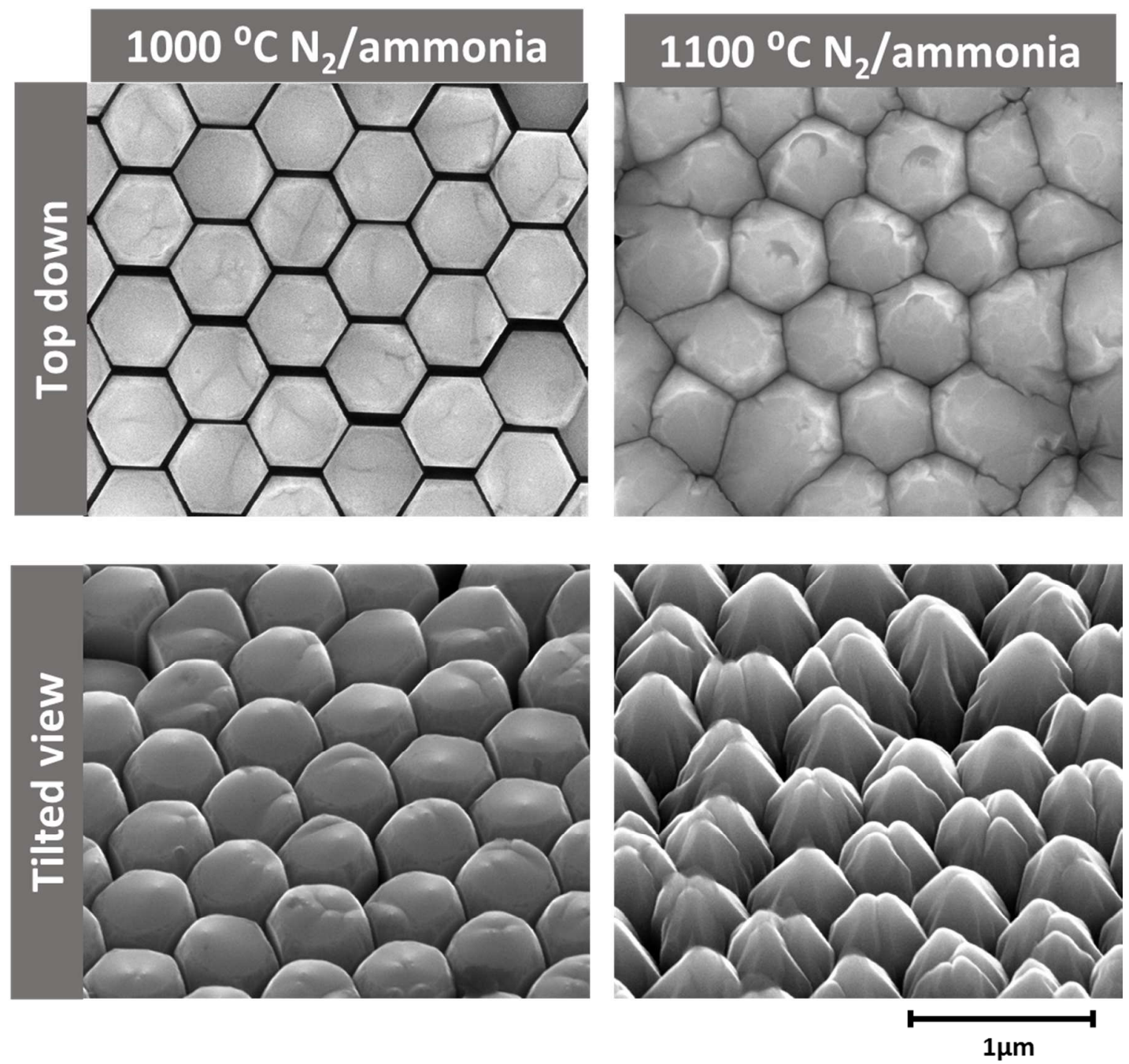

Figure S2. SEM scans plan view and tilted view revealing the roughened surface of the 1000 ${ }^{\circ} \mathrm{C}$ and $1100{ }^{\circ} \mathrm{C}$ anneal. 
$\mathrm{SiO}_{2}$ Coating Method

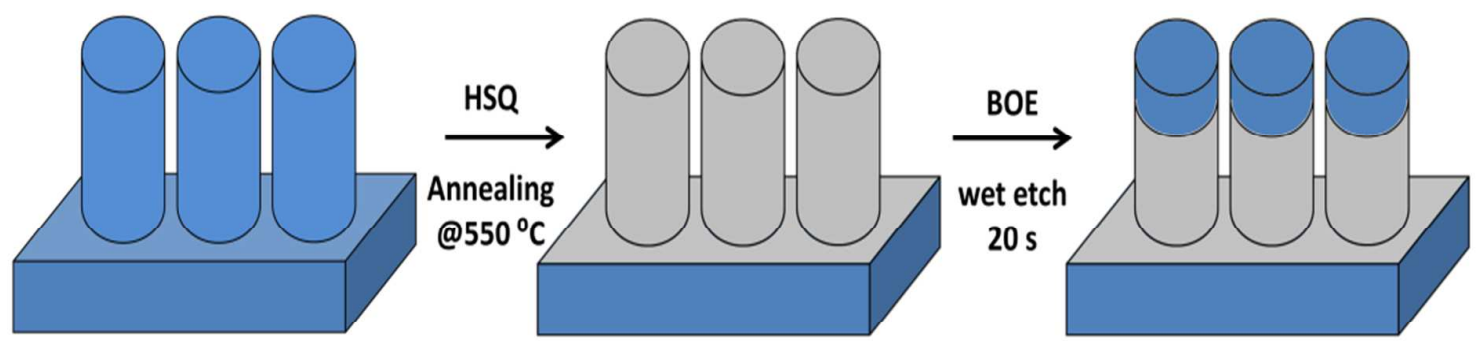

Figure S3. Schematic illustration of the hydrogen silsesquioxane (HSQ) coating of the nanorods and the controlled silica trimming by buffered oxide etchant (BOE) wet etch after the $550{ }^{\circ} \mathrm{C}$ anneal for $4 \mathrm{hrs}$. 
TEM of ex-situ $900{ }^{\circ} \mathrm{C}$ anneal
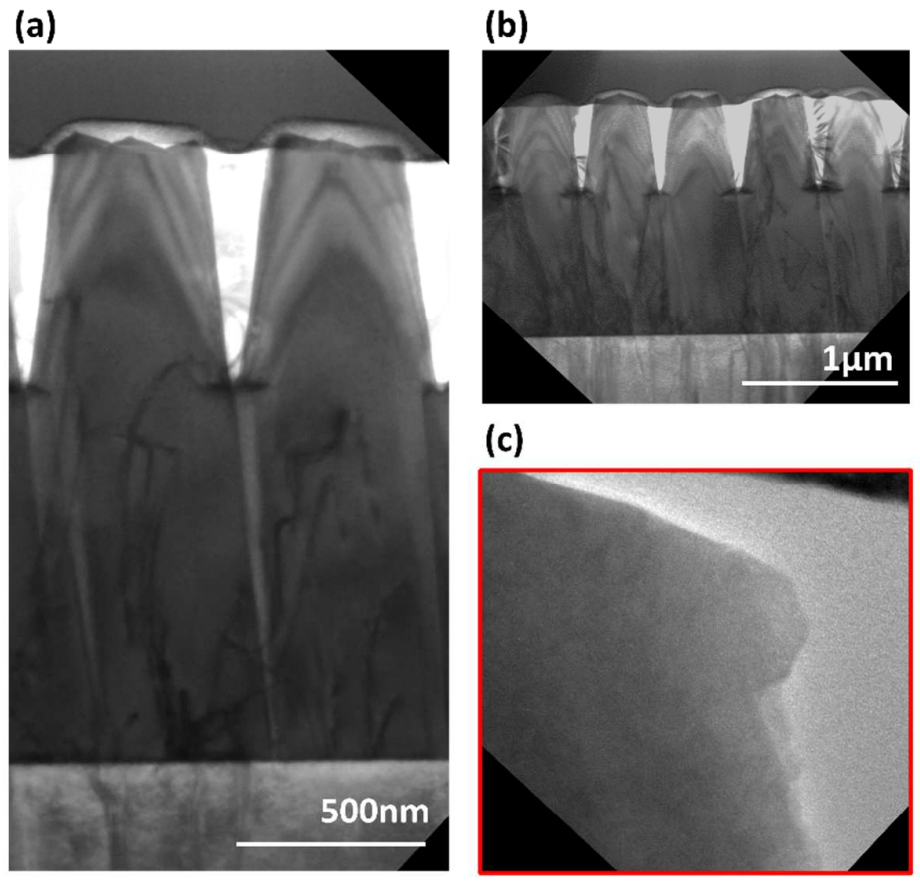

(d)

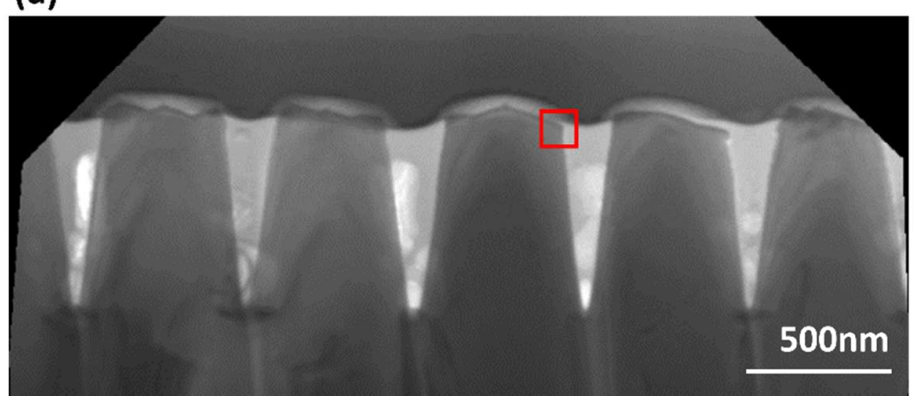

Figure S4. TEM imaging of the R2 silica coated type GaN nanorods after annealing in the MOCVD reactor (a) dislocations bent out the sidewalls, (b) dislocations seen in the un-etched bulk layer below the nanorods are not visible along most of the nanorod arrays, (c) overhang of the $\mathrm{GaN}$ at the top of the $\mathrm{SiO}_{2}$ coated sidewall, (d) GaN nanorod tops surfaces are irregular and rough. 
SEM crossectional measurment of height change

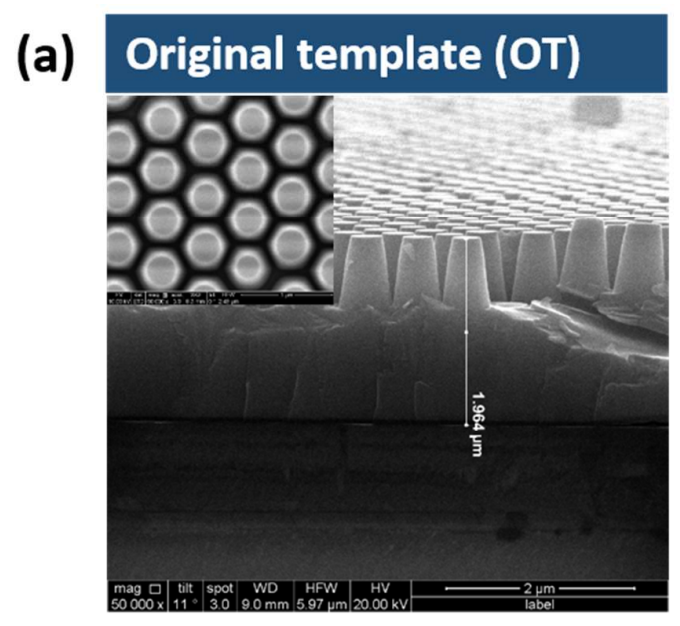

(b)
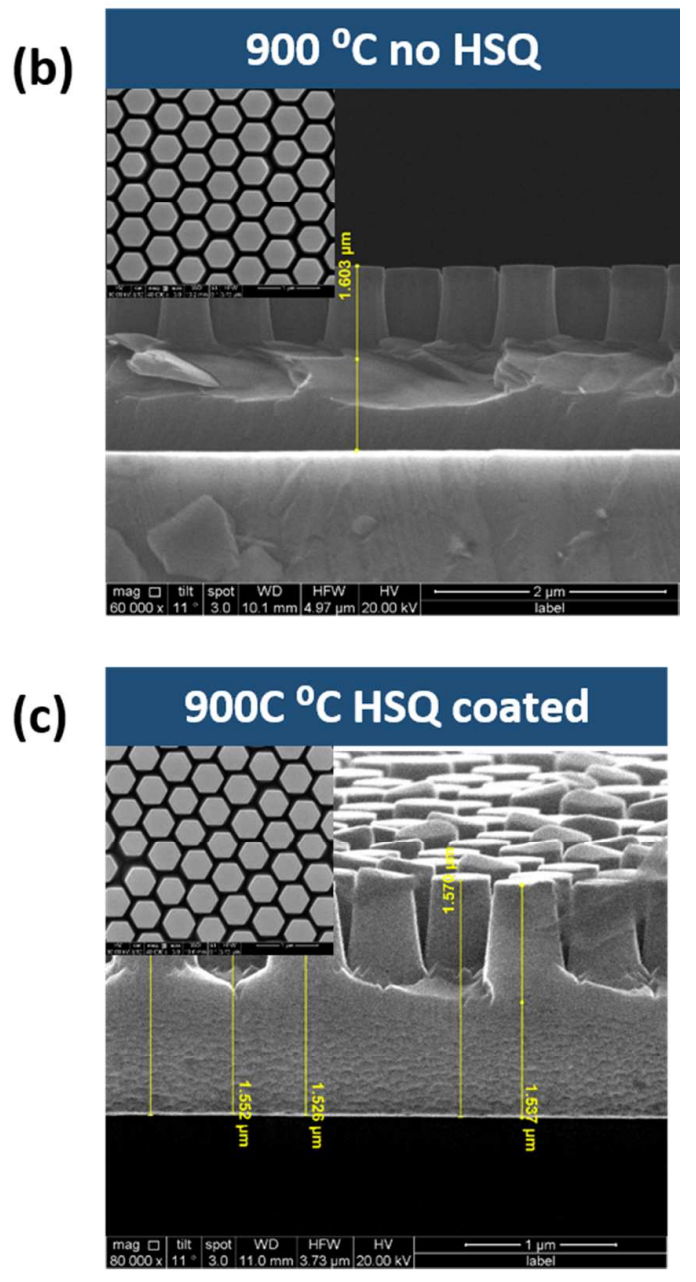

Figure S5. SEM cross section measurements of the change in height from the initial GaN/AlN interface up to the top of the nanorod: (a) etched nanorods, (b) nanorods of (a) annealed at $900{ }^{\circ} \mathrm{C}$, (c) $\mathrm{SiO}_{2}$ etched nanorods of (a) after annealing at $900{ }^{\circ} \mathrm{C}$. 
AFM line scan of the nanorod top surface

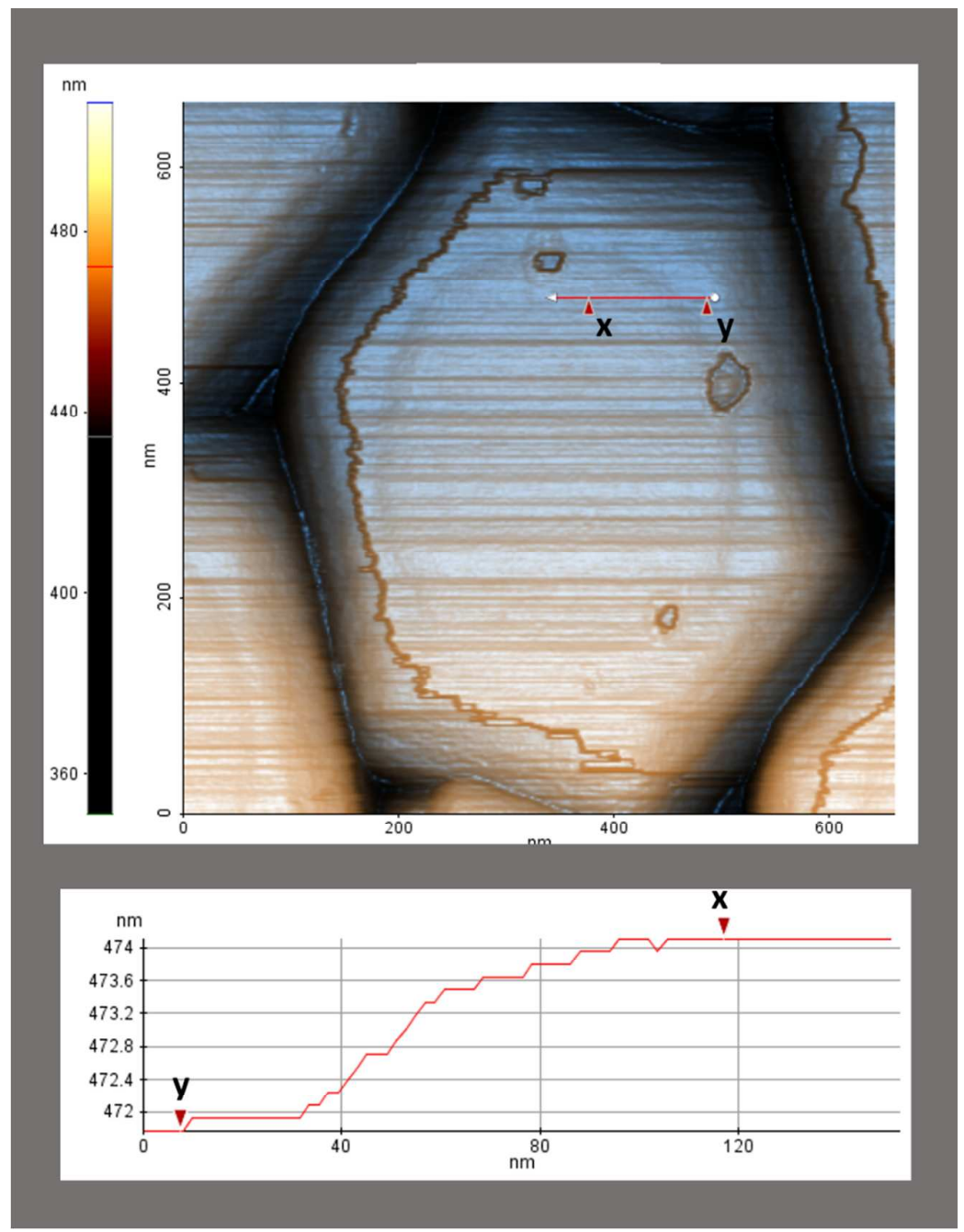

Figure S6. AFM line scan of the top surface shown in Figure $3 \mathrm{~b}$ of the main text. 


\section{CL hyperspectral emission energy strain mapping}

(a)

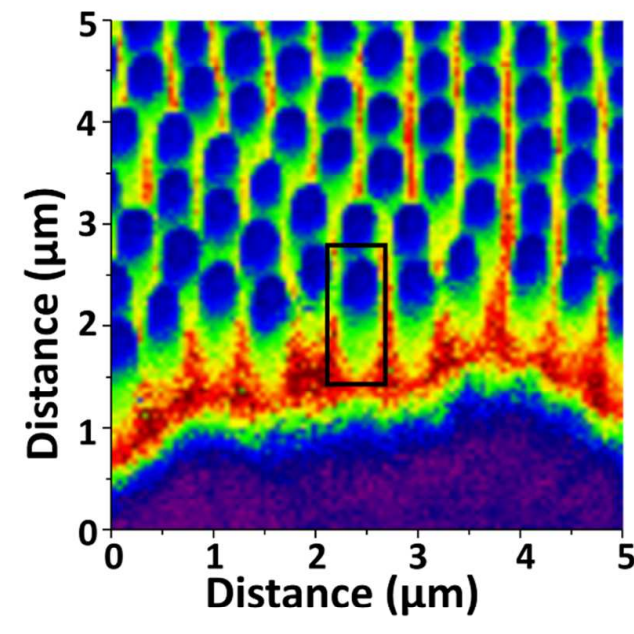

(b)

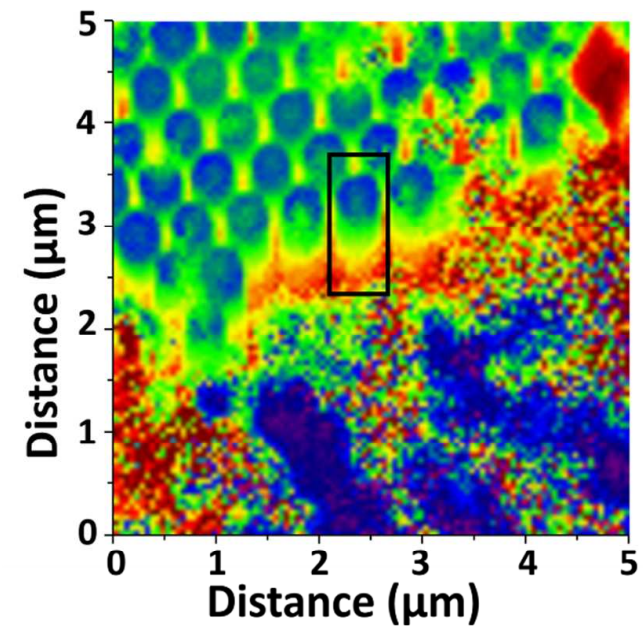

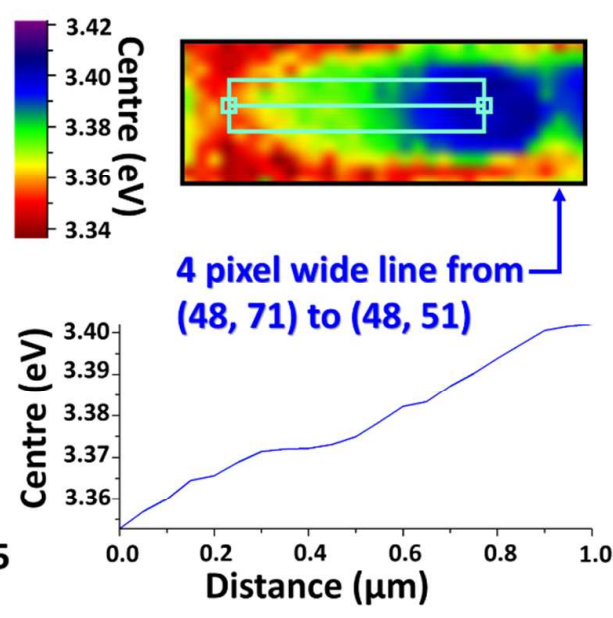

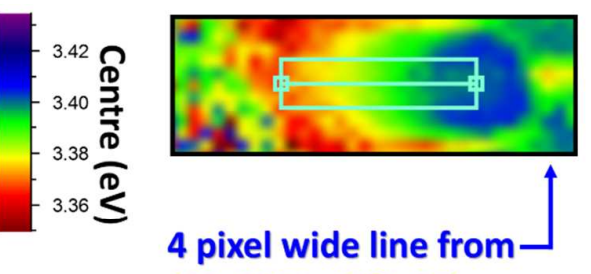

$(47,50)$ to $(47,33)$

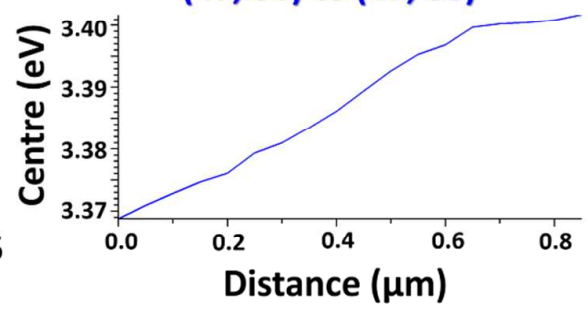

Figure S7. CL hyperspectral emission energy maps of the same areas seen in the intensity maps of Figure 5 (a) and (b) in the main article. (a) GaN nanorods after etching with inset of individual rod line scan, (b) GaN nanorods in (a) after $900{ }^{\circ} \mathrm{C}$ anneal with inset of individual line scan. 